OOPEN ACCESS

International Journal of Applied Research in Social Sciences

P-ISSN: 2706-9176, E-ISSN: 2706-9184

Volume 2, Issue 6, P.No. 144-151-, December, 2020

Fair East Publishers

Journal Homepage: www.fepbl.com/index.php/ijarss

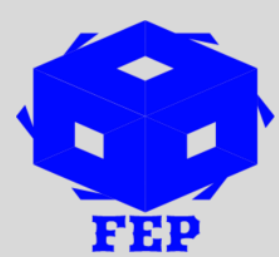

FEP

\title{
EXAMINING THE ROLE OF LINGUISTICS IN ENGLISH LANGUAGE TEACHING AS EFL AT HIGHER INSTITUTION: THE CASE OF METTU UNIVERSITY
}

\author{
Miressa Amenu $\mathrm{T}^{1}$ \\ ${ }^{1}$ Department of English Language and Literature, \\ College of Social Sciences and Humanities, Dambi Dollo University, \\ Dambi Dollo, Ethiopia
}

*Corresponding Author: Miressa Amenu T

Corresponding Author Email: mirre4boni@gmail.com

Article Received: 08-11-20 Accepted: 13-12-20

Published: $30-12-202$

Licensing Details: Author retains the right of this article. The article is distributed under the terms of the Creative Commons Attribution-Non Commercial 4.0 License (http://www.creativecommons.org/licences/by-nc/4.0/) which permits non-commercial use, reproduction and distribution of the work without further permission provided the original work is attributed as specified on the Journal open access page.

\begin{abstract}
This paper was aimed at examining the role of linguistics in English language teaching as a EFL at higher education. The participants of the study were summer students of English Language and literature department of Mettu University. Accordingly, all participants were selected through purposive sampling techniques for the questionnaire and interview. Quantitative and qualitative data were obtained and analyzed quantitatively and qualitatively. Thus, this study employed a mixed approach. The findings of the study revealed that all participants have reached on mutual understanding and well noted that linguistics and language teaching have the same subject matter to deal with the role of linguistics to play in the process of language teaching. Therefore it can be said that language is the fundamental unit of the branch of linguistics. Without languages the subject of linguistics cannot be there. In other words languages pave the way for the growth of the field of linguistics. A language is a mental phenomenon and a way of expression of thought by means of articulate sounds. On the other hand linguistics is a branch of study that deals with languages. Finally, the findings have significant implications for adoption of linguistics in teaching language. This is the reason why the role of linguistics in English language teaching is needed for language learners.
\end{abstract}

Keywords: Linguistics, Language, Language Teaching, Teaching, Role Of Linguistics 


\section{INTRODUCTION}

Today, English language possesses the largest population in the world: native and nonnative speakers and it has been given the position of an official language in the most of the countries in the world. On top of this, it has been using as the medium of instruction in the Universities among the countries over the world that has been perceived as key strategy through which universities propelled by academic, political, social and economic motives responded to the influence of globalizations (Altbach\& Knight, 2007).

Over the world people try to spend an immense amount of words in their life talking in order to communicate with other people in human societies. To this end, linguistic gives sensible persuading structure to language when all is said in done. Linguistics is concerned with the nature of language and communication. It deals both with the study of particular languages and the search for general properties common to all languages or large groups of languages. It includes the following subareas: phonetics (the study of the production, acoustics and hearing of speech sounds), phonology (the patterning of sounds), morphology (the structure of words), syntax (the structure of sentences), semantics (meaning), pragmatics (language in context). So, linguistics is a major that gives you insight into one of the most intriguing aspect of human knowledge of language. This has been fuelled by the fact that, English defined as the global common language of advanced education (Fishman, 2000).

Due to the value attached to the English language in the present times and the advantage of using it in the existing global language order, the relations between linguistics and languages teaching have been described as dual applications and implications and higher education has been the venue where English language medium instruction could be implemented more consistently in Ethiopian Universities. By understanding the role of linguistics in language teaching, one may have deeper insights into the nature of language, and act accordingly in teaching the language. The aim of this paper is to assess the role that linguistics has had on English language teaching as foreign language.

\section{REVIEW OF RELATED LITERATURE}

\section{The Concept of Linguistics}

Crystal, David (1990) Linguistics is the scientific study of language. Such study has, broadly speaking, three aspects: language form, language meaning, and language in context. Thus, linguistic refers to insights about language and when these insights are used to language teaching, it becomes linguistic principles.

Linguistics constitutes the most systematic study of language at our disposal. Linguistics is a subject developed by scholars who devote themselves to the explanation and detailed description of language phenomena. Linguistics has to play down the natural understanding that people have about languages in order to gain precision in description. Present day linguists as against traditional grammarians use a descriptive method which relies heavily on access to the intuitions of a native speaker.

Linguistics is usually defined as the science of language or the systematic study of language. As a science, it cultivates a rational outlook upon language. Linguistics is a theoretical science that formulates explanations which are designed to account for the phenomena of languages. It is also an empirical science making detailed observation on particular languages to refute generalizations. It is also a descriptive discipline, this contrast to the normative nature of much 
language study. The linguist accepts language as he finds it, observes it and explain why it is so. From a linguist's point of view, a language is what the speakers say and not what someone thinks they ought to be.

\section{The Concept of Language Teaching}

Language teaching is said to be the activities which are intended to bring about language learning. It is more widely interpreted than instructing a language class. Formal instruction and methods of training, preparation of teaching materials, as well as making the necessary administrative provision inside and outside an educational system all fall under the concept of language teaching.

According to stern (1983), a good language teaching would meet the conditions and needs of learners in the best possible ways. It would strive to provide a conceptual framework devised for identifying all factors relevant in the teaching of languages and the relationship(s) between them forgiving effective direction to the necessary research and enquiry.

Jesa (2008) argues that the aim of teaching English language is to make the learner an effective user of the language. He mentions of the general objectives of teaching English language as follows:

* In listening, the general objectives of teaching English are to enable the learner to comprehend English when spoken at normal conversational speed;

* In speaking, the general objectives of teaching English are to enable the learner to speak English with fluency, accuracy and appropriateness;

* In reading, the general objectives of teaching English are to enable the learner to read English with comprehension at a reasonable speed;

* In writing, the general objective of teaching English are to enable the learner to write English neatly and correctly.

\section{Linguistics in Language Teaching}

The obvious reason for considering the role of linguistics in relation to language teaching is that both in different ways have to do with language. It would be unreasonable for language teaching to disregard what linguistics has to say about language. Linguistics is the science of languages, and the major concern of all the Linguists is largely related to the finding and describing the characteristics of a particular language(s). The concern of linguistics as well as of language teaching is grammar, vocabulary and pronunciation. Hence both are concerned with different objectives with the same material, and have a give-and- take relationship. Linguistics has provided a number of grammars out of which better pedagogical grammars can be built. With the help of the phonetic alphabet and other phonetic insights, the learning-teaching of pronunciation has been greatly facilitated. The greatest contribution of linguistics is to increase one's understanding of the nature of language. Linguistics helps in taking fundamental decisions such as which languages are to be taught up to what time and at what level in an educational system. the main role of linguistics in language teaching is to produce good descriptions of languages. Then these descriptions of language serve as the input to language teaching materials( Wilkins (1972,p. 216).

Methods of language teaching like fashions have been changing along with the developments in linguistics. So linguistics helps in determining the place and position of a foreign language in a syllabus and also helps in determining the aims and objectives of the teaching of the target language. Since teaching is determined by syllabus, linguistics has great usefulness for the 
syllabus designer and can help him in determining, how, why, when and whom to teach. Since teaching is to take through txt-books, linguistics can help the text-book writer to prepare linguistically sound, learners' need-based textbooks. Linguistics can also contribute in the selection and gradation of vocabulary and structures. Linguistic is the general principles in which languages are constructed. Thus, both linguistic and language teaching take language as their subject (Freeman \& Freeman, 2004, p. 71).

The main role of linguistics in language teaching is to produce good descriptions of languages. From the linguistics levels of phonetics and phonology, language teaching have benefitted from the description of sounds of human languages. The primacy of speech in language teaching can be attributed to the influence of structural linguistics, the interest in the descriptive study of the spoken language. Phonetics studies speech sounds as such regardless of a particular language, while phonology investigates the sound system of a particular language. Phonetics can be considered as helpful to pronunciation teaching (oral) in that it provides the language teacher with a diagnostic understanding of how speech are produced. Phonology is needed to understand what constitutes the sound system of a particular languages and how the sounds are internalized by speakers for the purpose of communication. Linguistics and language teaching are often considered to be two very relevant fields of study for they have the same subject matter to handle. Linguistics as the study of language, a human phenomenon, is now an autonomous and well developed discipline of social science (D. A. Wilkins states, 1972, p.215).

\section{Importance of Linguistic in teaching Language in EFL context}

Although 'language' is the very substance of both linguistics and language teaching, many linguists by and large are not very clear about 'how' and 'how far' linguistics helps language teaching. Linguists like Noam Chomsky and many others came to the conclusion that linguistics can help language teaching (Chomsky, N. 1965).

According Varshney (1998) linguistics is science whereas language teaching is called as an art. This indicates that linguistics is important for language teaching because linguistics and language teaching can be likened to the relationship of knowledge about engine and the skill in driving a car. Linguistics always plays a vital role in studying language in general and English language in particular in ELT settings. Linguistics shares with human language even attribute to other sciences can help us to understand our language. Therefore, linguistics and language are closely intertwined, so discussion of one necessarily involves the other.

The role of language as an integral part of being human is increased among branches of linguistics such as psychology, sociology, anthropology and etc. In general, linguistics has always tried to answer the basic questions related to language: what is language? ; How does language work? Why do languages change in the history of human being? ; What do all languages over the world have not the same? Hence, these questions have been frequently discussed by language experts through the world. What is important is that the languages have in common in learning (Khansir and Tabande, 2014)

English language is taught as a second or foreign language around the world to school or university learners. English language has a special place in the educational system of foreign countries and no doubt, learning and teaching English requires English teacher should be master the English language skills, from this point of view, a knowledge of a linguistics is essential for English language teaching in general and English teacher, in particular. Because, the most major important role of linguistics in language is that has been concerned with solving or at 
least improving social problems involving language. In other words, in the modern educational setting, the English teacher is supposed to know linguistics or applied English linguistics in order to prove himself/herself as an effective English language teacher (AlamKhan, I., 2011). Linguistics is using what we know about (a) language, (b) how it is learned and (c) how it is used, in order to achieve some purpose or solve some problems in the real world" (Khansir, A.A., 2012a.). In recent years, the role of applied linguistics in English language teaching (ELT) has been considerable in designating English academic courses at universities, teacher training institutions, English materials and providing the programmes for English for specific or general purposes for English learners around world. In addition, the relation between Linguistics and language teaching is necessary, from of this point of view, Taylor (1987) pointed out that "some specific linguistics knowledge is required by the language teacher-for assessment, for choosing learning activities, for course planning and design." Halliday (1967) mentioned that the principle contribution of linguistics to language teaching is to provide a revealing description of the language being taught.

Johnson and Johnson (1999) argue that in the twentieth century, however, the role of linguistics on language teaching has been pre-eminent. They add that this is in part due to its high profile as a new and innovative discipline, and the general belief that it is the nature of language which is most relevant to language teaching. Teaching of English language in ELT classroom obviously depends on the English teachers, linguists, and syllabus designers. Linguistics always provides the best process of learning English language to the students. In the history of English language, there have been the several hypotheses in the linguistics field in order to offer the kind of English instruction to motivate the students in learning their English language. Thus, the major important aim of linguistics is to facilitate the process of language teaching in general and English language in particular. Language teaching is carried out in all kinds of different issues of linguistics. Linguistics as a language science is the foundation of language knowledge. Linguistic by itself is a part of language competence in English language teaching (Kramsch, 2009)

Linguistics as one of the language subjects has been discussed by great language scholars. Many language researchers have been evaluating place of linguistics in language teaching. The knowledge of linguistics is necessary in the teaching of foreign languages in general and English language in particular. Linguistics has influenced English language teaching. It is important is that linguistics increases English teachers ' understanding of the nature of language learning. In general, the aim of linguistics is to improve the process of language learning. Wilkins (1972) argues that for the language teacher the study of linguistics is probably more rewarding in this respect than in any other. He adds that we have seen a number of ways in which linguistics may help the language teacher to make more informed decision.

Language varies over the centuries, it varies geographically, and it also varies from situation to situation. We do not speak in the same way in all situations, for example, in a law court, a bar, at church, on the phone, at work, at a football match or to our friends, doctors, husbands, wives, bosses and children. A language cannot be accounted for by a uniform set of rules, which are always valid and always applied in the same way (Woolfolk, 2001). 


\section{METHODS}

This research aimed to examine the role of linguistic in teaching English Language of undergraduate EFL learners of Mettu University. Therefore, the qualitative research design was employed in this study with a descriptive research design.

\section{Research Site, Sampling, and Participants}

The site of the study was Mettu University in Oromiyaa, Ethiopia. The main subject of this study was EFL undergraduate learners of Mettu University. The participants were chosen by using purposeful sampling. The aim of this study was not for generalization, it developed deep examinations from a central phenomenon. It is supported by Creswell (2014) and Abrar et al., (2018) who emphasize that qualitative research does not necessarily having a large number of participants. Thus, the second summer students, having the smallest number of EFL students were chosen as the participants of this study in order to get closer relationship and deeper information from them.

\section{FINDINGS AND CONCLUSION}

The analysis of the data shows that linguistics plays a good number of roles in language teaching as linguistic refer to scientific study of language and language is a system of conventional spoken or written symbols used by people to communicate with each other, reflects a culture's way of thinking, and changes from one culture to another culture. This is the reason why one cannot isolate the linguistics phenomenon from language teaching. Therefore it can be said that language is the fundamental unit of the branch of linguistics. In fact without languages the subject of linguistics cannot be there. Aron (2011) argues that linguistics studies the nature of languages, the various phonetic changes that take place in the languages, the changes in the meanings of particular words in the course of time and the like.

In a foreign language classroom teachers need to know about the role of linguistics in foreign language classrooms is that language is characteristically complex. So, what linguistics has to do is to recognize the fundamentals or aspects in order to analyze it. For instance, to talk about a language we try to analyze it from four aspects such as sound system, grammatical system, lexical system and discourse system.

Based on the data obtained from questionnaire and interview it was found that each aspect of linguistics in English Language teaching as EFL at higher institution indicated that linguistics and language teaching are closely intertwined, so discussion of one necessarily involves the other. In that way linguistics helps teachers convey the origins of words and languages, their historical applications, and their modern day relevance.

In general, the participants reasonably agreed on the role of linguistic in English language teaching and some of which seem to be easy and quick to use the linguistics elements. It is widely held that the real contribution of linguistics in language teaching is to increase awareness and skills of the teacher. Therefore, Linguistics has offered to all those concerned with language teaching many a useful insight and awareness. In this relation, one should know how language works and express meaning, and what structures are used in the particular language she/he is teaching.

\section{Conclusion}

Based on the discussion above, it can be concluded some of the following. 
The present paper intended to study the role of linguistics in English Language teaching as EFL at higher institution. English is valued highly in Ethiopia with a lot of prestige being attached to the language. A lot of time and energy is dedicated to teach or learn English in the Ethiopian Universities as a major courses and common courses too. Thus, in English language instruction, the main thing that should be considered is linguistics components. As it is the application of the linguistic knowledge, the English language instruction will be well designed based on such components. Linguistics has the purpose to explore the general principles on which a language is constructed and operate as system of communication.

The target of contemporary foreign language teaching is to help learners to learn and to communicate in the target language. Knowledge of linguistics actually can help the English language teacher understand and handle English language rules through teaching- learning strategies. Willkins (1972) argues that the value of linguistics is that by increasing language teachers' awareness of language, it makes them more competent and therefore a better language teacher. However, the important of linguistics as a necessary means of language studies has been felt in English language classrooms.

In term of practical pedagogy, language needs linguistics in several different scientific works and linguistics can help to strengthen all the language issues in reaching to answer the fundamental questions of human language. Linguistics, as the science of language, should be fundamental importance for teachers of language.

In summary, linguistics has made the process of changing in English language teaching. So, English language teachers, syllabus designers have gained a large body of information from the study of linguistics. English teachers have increased their language knowledge from linguistics and they have acquired the methods, techniques, approaches, in order to improve English language teaching in foreign or second language settings. And based on the results, it can be concluded that linguistics is a field of study that examines language in a principled way.

\section{References}

Abrar, M., Mukminin, A., Habibi, A., Asyrafi, F., Makmur, M., \& Marzulina, M. (2018). "If our English isn't a language, what is it? Indonesian EFL student teachers' challenges speaking English. The Qualitative Report, 23(1), 129-145. Retrieved from http://nsuworks.nova.edu/tqr/vol.23/iss1/9

Alam-Khan, I. (2011). Challenges of Teaching/Learning English and Management. Global Journal of Human Social Science, 11(8).

Altbach, P. G., \& Knight, J. (2007). The internationalisation of higher education: Motivations and realities.' Journal of Studies in International Education, 11(3/4), 290-305.

Aron. (2011). Difference between Language and Linguistics. http://wwwdifferencebetween.com (accessed 30/2/2011).

Chomsky, Noam A. (1965). Aspects of the Theory of Syntax. Cambridge, MA: MIT Press.

Crystal, D. (1992). An Encyclopedic Dictionary of Language and Languages. USA: Black well Publishing.

Creswell, J. W. (2014). Research design qualitative, quantitative and mixed method approaches. London, England: SAGE. 
Freeman. D. E., \& Freeman, Y. S. (2004). Essential linguistics: What you need to know to teach reading, ESL, spelling, phonics, and grammar. Portsmouth, NH: Heinemann.

Jesa, M. (2008). Efficient English Teaching. New Delhi: A P H Publishing Corporation

Johnson, K., \& Johnson, H. (1999). Encyclopedic Dictionary of Applied Lingustics. UK: Blackwell Publishing.

Khansir, A.A., \& Tabande, Y. (2014). The Effects of Persian Language on Vocabulary Learning of Iranian EFL Students. International Journal of Language Learning and Applied Linguistics World (IJLLALW), 6, 3, 62-75.

Khansir, A.A. (2012a). Error Analysis and Second Language Acquisition. Theory and Practice in Language Studies, 2, 5, 1027-1032.

Kramsch, C. (2009). Language and Culture. China : Oxford University Press.

Wilkins, D.A.( 1972). Linguistics in Language Teaching. Edward Arnold Ltd. (Publishers). U.K.

Woolfolk, A. (2001). Educational Psychology (9th ed.). Boston: Allyn and Bacon. 